\title{
Downbeat Nystagmus Elicited by Eyelid Closure
}

\author{
João Lemos, MD, Daniela Pereira, MD, Margarida Amorim, MD, Beatriz Santiago, MD, \\ António Paiva, PhD, Luís Cunha, PhD
}

\begin{abstract}
We describe a patient with downbeat nystagmus (DBN) evoked only by eye closure. Brain and spinal cord magnetic resonance imaging revealed a T2 paramedian lesion in the left lower basis pontis and other white matter lesions consistent with multiple sclerosis. One potential mechanism for DBN in this case involves transverse ephaptic spread of excitation from areas that subserve coordinated lid closure to the decussating ventral tegmental tract.
\end{abstract}

Journal of Neuro-Ophthalmology 2014;34:350-353

doi: 10.1097/WNO.0000000000000123

○ 2014 by North American Neuro-Ophthalmology Society

D ownbeat nystagmus (DBN) is an ocular motor disorder with a slow spontaneous upward drift and a compensatory fast phase directed downward. If occurring spontaneously, it is most commonly caused by lesions of the cerebellar flocculus or paraflocculus, which are believed to disinhibit the upward vestibular system. Less commonly, DBN is associated with brainstem lesions located in medulla oblongata and/or pontine tegmentum, strategically involving the paramedian tract neurons, medial vestibular neurons, and/or its efferent tracts (1-8). Evoked forms of DBN exist, such as following head shaking in patients with focal pontine tegmentum infarction (9) and dorsomedial medulla oblongata demyelination (10). DBN occurring with eye closure has been reported in 2 patients in the pre-magnetic

Departments of Neurology (JL, BS, LC), Neuroradiology (DP), and Otorhinolaryngology (MA, AP), Coimbra University Hospital Center, Coimbra, Portugal.

The authors report no conflicts of interest.

Presented as a poster at the 39th Annual NANOS Meeting, February 11-16, 2013, Snowbird, UT.

Supplemental digital content is available for this article. Direct URL citations appear in the printed text and are provided in the full text and PDF versions of this article on the journal's Web site (www. jneuro-ophthalmology.com).

Address correspondence to João Lemos, MD, Department of Neurology, Coimbra University Hospital Center, Praceta Professor Mota Pinto, Coimbra 3000-075, Portugal; E-mail: merrin72@hotmail.com resonance imaging (MRI) era. Both had presumed peripheral vestibulopathy (11). DBN with eye closure may also occur in a small percentage of normal individuals (12). We describe a patient with dizziness and DBN occuring only with eyelid closure in whom a localized paramedian lesion of the lower basis pontis was detected.

\section{CASE REPORT}

A 43-year-old woman with no neurological history developed subacute asymmetric weakness and paresthesias of the lower limbs and urinary retention. Two weeks later, she experienced the sensation of rhythmic vertical eye movements and sustained to- and-fro- imbalance provoked only by voluntary eye closure. Examination demonstrated a T10 sensory level with impaired lower limb proprioception and vibration. She had bilateral extensor plantar responses. Muscle stretch reflexes were reduced bilaterally. Limb coordination was intact. To- and fro- truncal unsteadiness was evident when seated with a tendency to fall backwards only with eyes closed.

Visual acuity was 20/20 in both eyes, pupils had normal reactions, and the fundi were normal. The patient had normal eye alignment and full ocular motility without spontaneous, gaze-evoked, positional, hyperventilation-induced, or headshaking nystagmus with or without fixation (Frenzel lens). Video-guided direct occlusive ophthalmoscopy (13) did not show any nystagmoid movements (See Supplemental Digital Content, Video, http://links.lww.com/WNO/A98). Pursuit was smooth, saccades showed normal range and velocity, and the horizontal and vertical head thrust test was normal. Continuous ryhthmic vertical ocular excursions were evident under closed lids, associated with fore and aft postural instability (See Supplemental Digital Content, Video, http://links.lww.com/WNO/A98). There was no associated eyelid muscular contraction. No abnormal movements of the soft palate were seen either with eyes open or closed.

Two weeks after onset of symptoms, brain MRI revealed a small left paramedian lesion located at the level of the 
lower basis pontis near the pontomedullary junction, without involvement of the tegmentum. This lesion showed a hyperintense signal on T2 imaging and nodular enhancement (Fig. 1). No other lesions were detected in the cerebellum, medulla, or midbrain. However, 9 hyperintense lesions were present in the hemispheric periventricular white matter with an enhancing thoracic cord hyperintensity. Cerebrospinal fluid studies demonstrated a normal cell count, glucose, and protein levels with no oligoclonal bands. The multiplicity, distribution and the presence of both enhancing and nonenhancing lesions were highly suggestive of multiple sclerosis.

On 2 separate occasions, eye movements were recorded in light, darkness, and in the absence of fixation by videonystagmography (VNG) (VNG Ulmer version C4, resolution of $0.1^{\circ}$, sampling rate of $100 \mathrm{~Hz}$; Synapsys, Marseille, France) and in light, darkness, and with eyes closed using simultaneous horizontal and vertical electronystagmography (ENG) (4-channel Hortman CNG analyzer, DC-coupled, sampling rate of $50 \mathrm{~Hz}$; Hortmann Neuro-otometrie, Neckartenzlingen, Germany). Using VNG, there was no
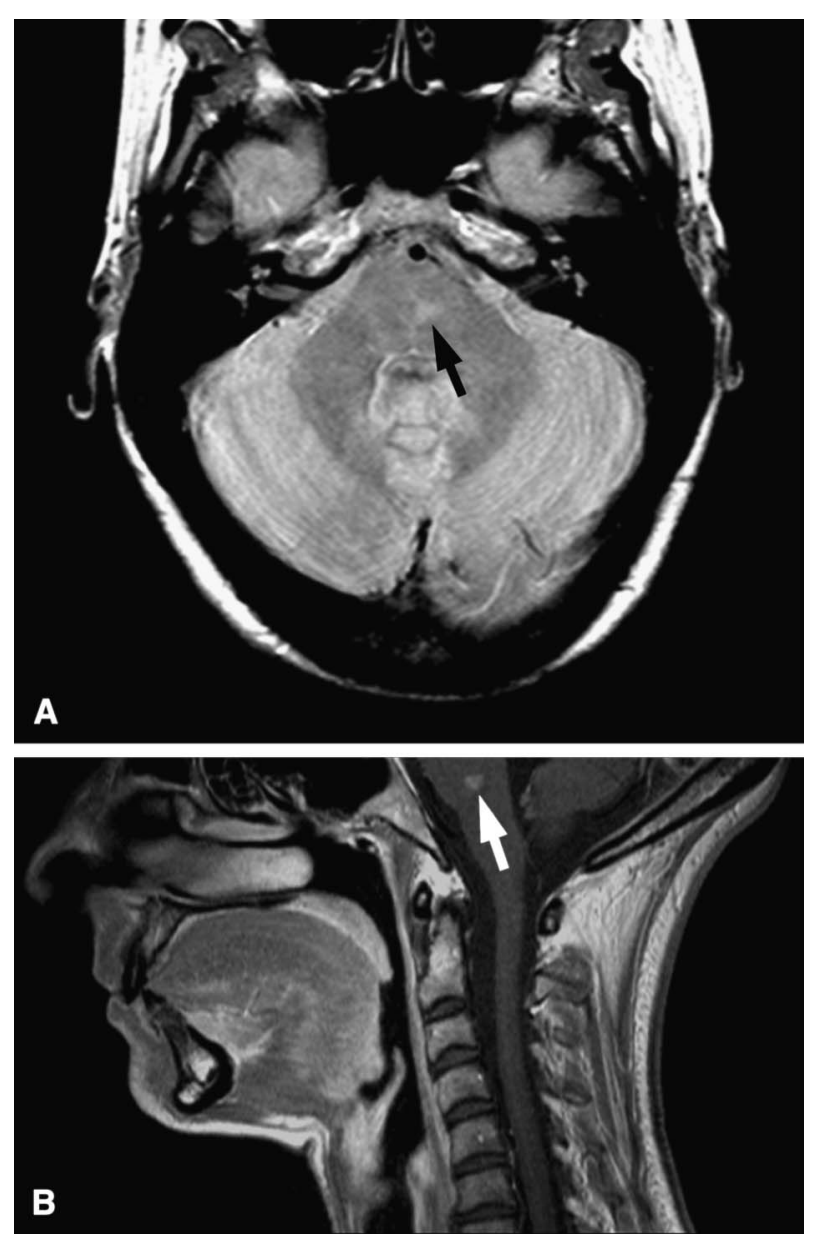

FIG. 1. T2 axial (A) and postcontrast T1 sagittal (B) magnetic resonance imaging shows a hyperintense lesion (arrow) in the vicinity of the crossing tegmental tract. evidence of spontaneous nystagmus in primary position in light (Fig. 2A), dark, or absence of fixation. Horizontal $20^{\circ}$ and vertical $15^{\circ}$ saccades at a frequency of $0.3 \mathrm{~Hz}$ had normal latency, velocity, and accuracy. Sinusoidal horizontal $30^{\circ}$ pursuit at a frequency of $0.3 \mathrm{~Hz}$ showed normal gain. Vertical pursuit, caloric and rotational testing were not performed. ENG with eyes open in light and in darkness (Fig. 2B) failed to demonstrate spontaneous nystagmus in primary position, but with eyes closed, there was persistent and reproducible DBN (slow phase velocity $18 \%$; amplitude $3.8^{\circ}$; frequency $1.9^{\circ} / \mathrm{s}$ ) (Fig. 2C).

The patient was hospitalized and treated with intravenous methylprednisolone 1,000 mg daily for 5 days and was subsequently started on interferon beta-1b for probable multiple sclerosis. She refused any symptomatic treatment for nystagmus. After 9 months, motor and sensory involvement had completely resolved, whereas DBN and unsteadiness evoked by eye closure were unchanged. The patient continued to show no evidence of palatal myoclonus.

\section{DISCUSSION}

DBN caused by focal brainstem lesions $(3,4,6-10)$ has been reported in a variety of clinical settings: spontaneous DBN (3,5-8), DBN (perverted) after horizontal head shaking with (10) or without associated spontaneous nystagmus (9), convergence-induced DBN in a patient with spontaneous upbeat nystagmus (UBN) (4), and spontaneous DBN replacing UBN (2). The presumed brainstem lesions causing DBN were located in the medulla (3-5), specifically in the paramedian medullary region $(2,6,10)$, pontomedullary junction (7), and the pontine paramedian tegmentum $(8,9)$.

The proposed mechanism for DBN requires a hyperactive vestibular system carrying anterior canal information, including the superior vestibular nucleus and its afferent connections to the third nerve subnucleus through the medial longitudinal fasciculus, brachium conjuntivum, and the ventral tegmental tract (VTT) (14). Generation of upward slow phases is followed by corrective downward quick phases creating DBN (1).

This series of events may occur through 2 potential pathways. First, paramedian tract neurons, excite the floccular/parafloccular region that inhibits vestibular pathways carrying anterior canal information $(6,8)$. With a lesion of the paramedian tract neurons, this inhibition is lost promoting hyperactivity of the anterior canal system. Alternately, damage of the downward vestibular system carrying posterior canal information constituted by the medial vestibular neurons and their afferent connections would lead to hyperactivity of the anterior canal system and DBN $(3,14)$.

Our patient had an isolated paramedian lesion in basis pontis without apparent involvement of neighboring structures. However, VTT is located near the transition between 


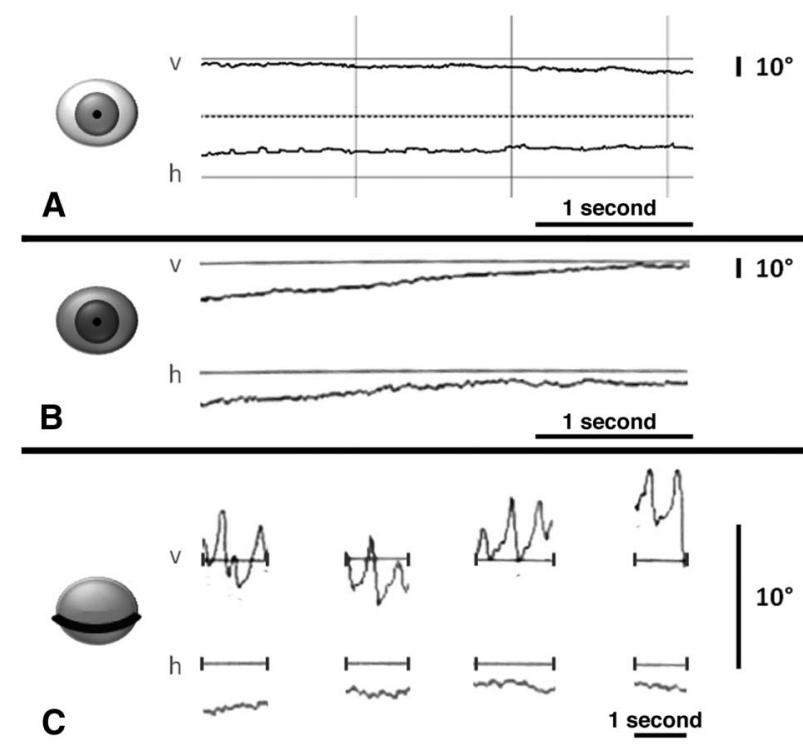

FIG. 2. Vertical and horizontal eye position (degrees) over time (seconds) from monocular recordings of the left eye. A. Videonystagmography with both eyes open in light, fixating a target at $60 \mathrm{~cm}$. No nystagmus is seen. B. Electronystagmography (alternate current) with both eyes open in the dark in the absence of fixation. No nystagmus is seen. C. Electronystagmography (alternate current) with both eyes closed. DBN is seen with exponentially increasing slow phase velocity waveform in the majority of the complexes. No consistent horizontal component is seen. Eye movements up and left are represented by an upward deflection of the tracing, whereas down and right are represented by a downward deflection. The upper traces in $(\mathbf{A}),(\mathbf{B})$, and $(\mathbf{C})$ represent the vertical component $(\mathrm{v})$, whereas the lower traces represent the horizontal component (h). basis and tegmentum in the pons, particularly at the level of its decussation (15), which coincides with our patient's lesion. Although VTT damage and subsequent hypoactivity is the pathophysiological mechanism for UBN in a number of case reports $(9,14-16)$, its hyperactivity theoretically could generate DBN. We believe that DBN with eyelid closure is due to transverse emphatic spread of excitation from a demyelinating plaque in paramedian pons, to both VTTs (or to its decussation). By activating this tract, a relative hyperactivity in the final vestibular pathways conveying anterior canal signals is promoted, inducing upward slow eye movement and compensatory fast-phase downward beating movement, resulting in DBN. Additionally, normal upward deviation of the eye under eye closure (Bell phenomenon) could promote an addictive effect (17).

Paroxysmal attacks are a well-known feature in patients with multiple sclerosis, and transversely spreading ephaptic activation of axons in partially demyelinated lesions is one of the mechanisms that may explain these phenomena (18). These attacks may be precipitated by movement of the limbs (19) or neck, hyperventilation, rising quickly (19), visual perception of movement (20), lateral gaze (21), or touch. In our patient, voluntary eye closure provoked sustained and reproducible DBN. In animal experimental data, eyelid closure was achieved not only with electrical stimulation of pontine tegmentum, but also with stimulations made more ventrally and mesially (22). The lesion in our patient could potentially involve the areas that subserve coordinated lid closure in the midpons. Their activation could excite contiguous tracts including the VTT, by transverse ephaptic spread of excitation. With eye opening, this spread of excitation would cease, and DBN abates (Fig. 3).
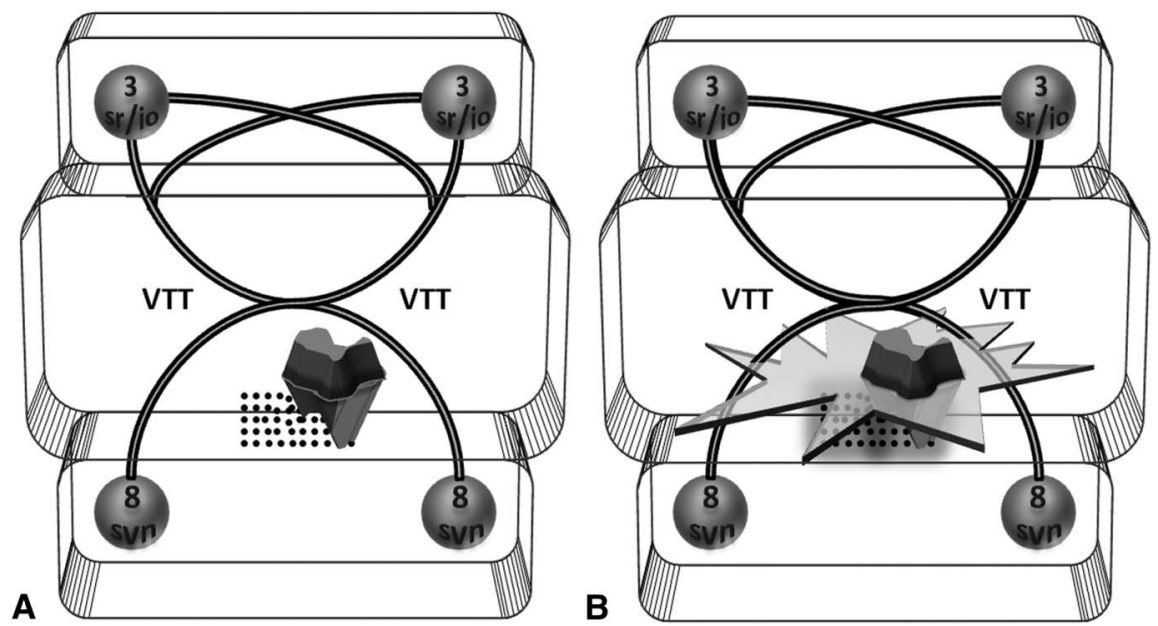

FIG. 3. Schematic drawing of brainstem, showing the left paramedian pontine lesion, regions that subserve eye closure (dotted areas) and the 2 ventral tegmental tracts connecting the superior vestibular nucleus with the third nerve nucleus, possibly decussating at the level of midpons. When both eyes are open $(\mathbf{A})$, no pathological vestibular imbalance occurs. Immediately after eye closure (B), ephaptic spread of excitation will activate the contiguous ventral tegmental tracts, causing paroxysmal vestibular imbalance and downbeat nystagmus. $3=$ third nerve nucleus; $\mathrm{sr}=$ superior rectus motoneurons; io = inferior oblique motoneurons; VTT = ventral tegmental tract; $8=$ vestibular nucleus; svn = superior vestibular nucleus. The upper, mid, and lower rectangles in $(\mathbf{A})$ and $(\mathbf{B})$ depict the midbrain, pons, and medulla, respectively. 
An alternative mechanism is that our patient developed a form of oculopalatal tremor (OPT). Eye closure has been reported to provoke pendular nystagmus in a series of patients with OPT, showing no nystagmus with eyes open (23). However, the presence of nystagmus with an apparent jerk component in the majority of the ENG complexes and the absence of damage of Mollaret triangle structures and/or inferior olivary hypertrophy on MRI makes this diagnosis less likely in our patient. After 9 months of follow-up, there is still no evidence of palatal myoclonus, either with eyes open or closed (24). A final possibility accounting for the presence of DBN in our patient could be based on involvement of the paramedian tract neurons and/or its connections instead of the proposed hyperexcitation of both VTTs. Involvement of paramedian tract neurons in our case could have to have escaped detection on MRI (25).

\section{ACKNOWLEDGMENTS}

The authors gratefully acknowledge Dr Eric Eggenberger for his helpful comments and suggestions.

\section{REFERENCES}

1. Leigh RJ, Zee DS. Diagnosis of nystagmus and saccadic intrusion. In: Leigh RJ, Zee DS, eds. Neurology of Eye Movements. 4th edition. New York, NY: Oxford University Press, 2006:475-558.

2. Rousseaux M, Dupard T, Lesoin F, Barbaste P, Hache JC. Upbeat and downbeat nystagmus occurring successively in a patient with posterior medullary haemorrhage. J Neurol Neurosurg Psychiatry. 1991;54:367-369.

3. Bertholon P, Convers P, Barral FG, Duthel R, Michel D. Syringomyélobulbie post-traumatique et nystagmus inférieur [in French]. Rev Neurol (Paris). 1993;149:355-358.

4. Fetter M, Dichgans J. Upbeat nystagmus changing to downbeat nystagmus with convergence in a patient with a lower medullary lesion. Neuroophthalmology. 1990;10:89-95.

5. Yeow YK, Tjia TL. The localizing value of downbeat nystagmus. Singapore Med J. 1989;30:273-276.

6. Nakamagoe K, Shimizu K, Koganezawa T, Tamaoka A. Downbeat nystagmus due to a paramedian medullary lesion. J Clin Neurosci. 2012;19:1597-1599.

7. Wagner J, Lehnen N, Glasauer S, Rettinger N, Buttner U, Brandt T, Strupp M. Downbeat nystagmus caused by a paramedian ponto-medullary lesion. J Neurol. 2009;256:1572-1574.

8. Nakamagoe K, Fujizuka N, Koganezawa T, Yamaguchi T, Tamaoka A. Downbeat nystagmus associated with damage to the medial longitudinal fasciculus of the pons: a vestibular balance control mechanism via the lower brainstem paramedian tract neurons. J Neurol Sci. 2013;328:98-101.

9. Kim HA, Lee H, Sohn SI, Kim JS, Baloh RW. Perverted head shaking nystagmus in focal pontine infarction. J Neurol Sci. 2011;301:93-95.

10. Minagar A, Sheremata WA, Tusa RJ. Perverted head-shaking nystagmus: a possible mechanism. Neurology. 2001;57: 887-889.

11. Kitamura K. Downbeat nystagmus during eye closure. J Laryngol Otol. 1987;101:1075-1078.

12. Fluur E, Eriksson L. Nystagmographic recording of vertical eye movements. Acta Otolaryngol. 1961;53:486-492.

13. Pereira T, Barbeiro P, Lemos J, Morgado M, Silva E. Digital Image Acquisition for Ophthalmoscope: Bioengineering (ENBENG), 2012. Paper presented at IEEE 2nd Portuguese Meeting, 23-25 February 2012; Coimbra, Portugal; 2012; 1-6.

14. Pierrot-Deseilligny C, Milea D. Vertical nystagmus: clinical facts and hypotheses. Brain. 2005;128:1237-1246.

15. Pierrot-Deseilligny C, Milea D, Sirmai J, Papeix C, RivaudPechoux S. Upbeat nystagmus due to a small pontine lesion: evidence for the existence of a crossing ventral tegmental tract. Eur Neurol. 2005;54:186-190.

16. Tilikete C, Milea D, Pierrot-Deseilligny C. Upbeat nystagmus from a demyelinating lesion in the caudal pons. J Neuroophthalmol. 2008;28:202-206.

17. Takemori S. Eye movements associated with eye closure. I. Normal subjects. ORL J Otorhinolaryngol Relat Spec. 1979;41:100-106.

18. Ostermann PO, Westerberg CE. Paroxysmal attacks in multiple sclerosis. Brain. 1975;98:189-202.

19. Yamamoto M, Yabuki S, Hayabara T, Otsuki S. Paroxysmal itching in multiple sclerosis: a report of three cases. J Neurol Neurosurg Psychiatry. 1981;44:19-22.

20. Khan OA, Sandoz GM, Olek MJ, Kuta AJ. Visually induced paroxysmal nausea and vomiting as presenting manifestations of multiple sclerosis. J Neurol Neurosurg Psychiatry. 1995:59:342-343.

21. Keane JR. Gaze-evoked blepharoclonus. Ann Neurol. 1978;3:243-245.

22. Weinstein EA, Bender MB. Integrated facial patterns elicited by stimulation of the brain stem. Arch Neurol Psychiatry. 1943;50:34-42.

23. Jacobs L, Bender MB. Palato-ocular synchrony during eyelid closure. Arch Neurol. 1976;33:289-291.

24. Kim JS, Moon SY, Choi KD, Kim JH, Sharpe JA. Patterns of ocular oscillation in oculopalatal tremor: imaging correlations. Neurology. 2007;68:1128-1135.

25. O'Riordan JI, Losseff NA, Phatouros C, Thompson AJ, Moseley IF, MacManus DG, McDonald WI, Miller DH. Asymptomatic spinal cord lesions in clinically isolated optic nerve, brain stem, and spinal cord syndromes suggestive of demyelination. J Neurol Neurosurg Psychiatry. 1998;64:353357. 